OPEN ACCESS

Edited by:

Mallikarjuna Korivi,

Zhejiang Normal University, China

Reviewed by:

I-Shiung Cheng,

National Taichung University of

Education, Taiwan

Subir Das,

College of Medicine \& JNM

Hospital, India

*Correspondence:

Chiao-Nan Chen

chiaonanchen@gmail.com

Specialty section:

This article was submitted to

Cardiovascular Metabolism,

a section of the journal

Frontiers in Cardiovascular Medicine

Received: 10 May 2021

Accepted: 19 July 2021

Published: 16 August 2021

Citation:

Chen C-N, Hsu K-J, Chien K-Y and Chen J-J (2021) Effects of Combined High-Protein Diet and Exercise Intervention on Cardiometabolic Health in Middle-Aged Obese Adults: A Randomized Controlled Trial.

Front. Cardiovasc. Med. 8:705282. doi: $10.3389 / f c v m .2021 .705282$

\section{Effects of Combined High-Protein Diet and Exercise Intervention on Cardiometabolic Health in Middle-Aged Obese Adults: A Randomized Controlled Trial}

\author{
Chiao-Nan Chen ${ }^{1 *}$, Kuo-Jen Hsu ${ }^{1}$, Kuei-Yu Chien ${ }^{2}$ and Jeu-Jung Chen ${ }^{1,3}$ \\ ${ }^{1}$ Department of Physical Therapy and Assistive Technology, School of Biomedical Science and Engineering, National Yang \\ Ming Chiao Tung University, Taipei, Taiwan, ${ }^{2}$ Graduate Institute of Sports Science, National Taiwan Sport University, Taoyuan, \\ Taiwan, ${ }^{3}$ Department of Rehabilitation, Taiwan Adventist Hospital, Taipei, Taiwan
}

Background: Obesity is the main risk factor of cardiovascular diseases (CVD) and metabolic diseases. The middle-aged population is the age group with the highest prevalence of obesity. Thus, improving cardiometabolic health is important to prevent CVD and metabolic diseases in middle-aged obese adults. The aim of this study was to examine the effects of exercise alone or in combination with a high-protein diet on markers of cardiometabolic health in middle-aged adults with obesity.

Methods: Sixty-nine middle-aged adults with obesity were assigned randomly to the control group (C; $n=23$ ), exercise group ( $E ; n=23$ ), or exercise combined with high-protein diet group (EP; $n=23$ ). Individuals in the $E$ and EP groups received supervised exercise training and individuals in the EP group received high-protein diet intervention. Body composition (assessed by dual-energy X-ray absorptiometry), oral glucose tolerance test (OGTT), lipid profiles, and inflammatory markers were determined before and after 12 weeks of intervention. Insulin sensitivity index $\left(\mathrm{ISI}_{0,120}\right)$ was calculated from values of fasting and 2 -h insulin and glucose concentration of OGTT. Insulin-peak-time during the OGTT was recorded to reflect $\beta$-cell function. Analysis of covariance with baseline values as covariates was used to examine the effects of the intervention. The significant level was set at 0.05 .

Results: After 12 weeks of intervention, the $\mathrm{E}$ group had a greater percentage of individuals with early insulin-peak-time during the OGT than that in the $\mathrm{C}$ and EP groups $(p=0.031)$. EP group had lower total cholesterol and triglycerides than that in the $C$ group ( $p=0.046$ and 0.014 , respectively). Within-group comparisons showed that the 2-h glucose of OGTT and C-reactive protein decreased in the EP group $(p=0.013$ and 0.008 , respectively) but not in the $E$ and $C$ groups; insulin sensitivity improved in the EP group ( $p=0.016)$ and had a trend to improve in the $E$ group $(p=0.052)$; and abdominal fat mass and total body fat mass decreased in both intervention groups $(p<0.05)$. 
Conclusion: Combined high-protein diet and exercise intervention significantly decreased fat mass and improved lipid profiles, insulin sensitivity, glucose tolerance, and inflammation in middle-aged adults with obesity.

Clinical Trial Registration: Thai Clinical Trials Registry, TCTR20180913003, 13-09-2018.

Keywords: obesity, glucose homeostasis, insulin, oral glucose tolerance test, aerobic exercise

\section{INTRODUCTION}

Obesity is the main risk factor of metabolic diseases, cardiovascular diseases (CVD), and some types of cancer (1-3). The middle-aged population is the age group with the highest prevalence of obesity (4). Therefore, establishing effective evidence-based strategies to decrease CVD risks in the middle-aged population with obesity is a major research priority.

Biomarkers of cardiometabolic health include insulin sensitivity, lipid profiles, and markers of inflammation $(5,6)$. Increased visceral fat of individuals with obesity causes glucose intolerance, impaired lipid profiles, and greater inflammatory cytokines than individuals with normal weight (7-9). A metaanalysis reported that the risk of CVD mortality increased 13\% per $88.5 \mathrm{mg} / \mathrm{dl}$ triglycerides (TG) increment (5). Postmenopausal women with the highest levels of total cholesterol (CHOL) combined with the highest levels of C-reactive protein (CRP) were 5 times at risk for CVD than individuals with the lowest levels of CHOL combined with the lowest levels of CRP (10).

Exercise and nutrition are fundamental strategies to improve the cardiometabolic health of individuals. Exercise, especially aerobic exercise, decreases fat mass and inflammation and improves lipid profile and insulin sensitivity in overweight/obese individuals regardless of age (11-13). Calorie restriction is a commonly used diet intervention for individuals with obesity. However, long-term engagement of calorie restriction for most middle-aged individuals is challenging. Recently, increasing evidence demonstrated the benefit of high-protein diet in individuals with obesity. Studies found that high-protein diet (20-30\% energy intake from protein) increased satiety and induced sustained reductions in appetite $(14,15)$. In addition, high-protein diets ( $\geq 25 \%$ energy intake from protein) have been shown to decrease body weight and fat mass and improve insulin sensitivity and blood pressure in individuals with obesity and patients with diabetes $(16,17)$.

Collectively, obesity in the middle-aged population requires attention and management to prevent obesity-related diseases. Research has shown that both exercise and high-protein diets have potential to be beneficial for the cardiometabolic health of individuals with obesity $(13,17)$. While many studies investigating the effects of exercise and nutrition found that highprotein diets/protein supplementation combined with exercise have stronger beneficial effects on skeletal muscle functions and physical functions than exercise alone $(18,19)$, the knowledge about the effects of exercise alone or in combination with highprotein diet on markers of the cardiometabolic health is lacking. In this regard, this study aimed to examine the effects of exercise alone or in combination with high-protein diet on markers of cardiometabolic health in middle-aged adults with obesity.

\section{METHODS \\ Participants}

The complete description of participant recruitment and randomization has been previously published (19). Briefly, 69 middle-aged (range: $50-64$ years old; mean: $58.3 \pm 0.5$ years old) individuals (63 females and 6 males) with obesity (body mass index (BMI): $27.7 \pm 0.4 \mathrm{~kg} / \mathrm{m}^{2}$; body fat: $41.5 \pm 0.6 \%$; waist circumference: $90.9 \pm 1.0$ centimeters) were randomly assigned into the control group $(\mathrm{C})$, the exercise group $(\mathrm{E})$ or the exercise combined with high-protein diet group (EP) and received 12 weeks of intervention. The prevalence of hypertension and type 2 diabetes mellitus (T2DM) was similar among the 3 groups $(\sim 1 / 3$ hypertension, and 1/5 T2DM). Participants in the EP group had a 4 times higher prevalence of dyslipidemia (35\%) than participants in the $\mathrm{C}(9 \%)$ and $\mathrm{E}$ groups (9\%). This study was approved by the Institutional Review Board of the National Yang-Ming University and all the participants signed the consent form (IRB number: YM-106064F-1).

\section{Exercise Intervention}

As shown in the Figure 1, individuals in the E and EP groups received supervised exercise training on the spin bikes in a fitness room. The duration of each session was $60 \mathrm{~min}$, including $10 \mathrm{~min}$ of warm-up, $30 \mathrm{~min}$ of high-intensity interval training (HIIT), and $20 \mathrm{~min}$ of cool-down and stretching. High-intensity interval training consisted of 5 cycles of 3-min of high-intensity exercise and 3-min of low-intensity exercise. The high-intensity was set at $90 \%$ of $\mathrm{HR}_{\text {peak }}$ or at 15 of the Borg 6-to-20 rating of perceived exertion (RPE) scale. The low-intensity was set at $70 \% \mathrm{HR}_{\text {peak }}$ or at 12 of the RPE scale. A graded exercise test on a cycle ergometer with a metabolic system (Cortex Metalyzer $3 \mathrm{~B}$, Germany) was used to determine the $\mathrm{HR}_{\text {peak }}$. Heart rate monitors (Polar RS400, USA) were used to ensure participants exercised at the target exercise intensity. The average attendance rate of exercise training of the $\mathrm{E}$ and $\mathrm{EP}$ groups was 90 and $94 \%$, respectively. The average $\mathrm{HR}$ at the high-intensity component of $\mathrm{HIIT}$ was $91 \% \mathrm{HR}_{\text {peak }}$ and $90 \% \mathrm{HR}_{\text {peak }}$ for the $\mathrm{E}$ and the $\mathrm{EP}$ groups, respectively. The attendance rates and training intensity were similar between the $\mathrm{E}$ and the EP groups.

\section{Diet Intervention}

The target protein intake of this study was $1.6 \mathrm{~g} / \mathrm{kg} / \mathrm{day}$, which is higher than the current recommended dietary allowance (RDA) 


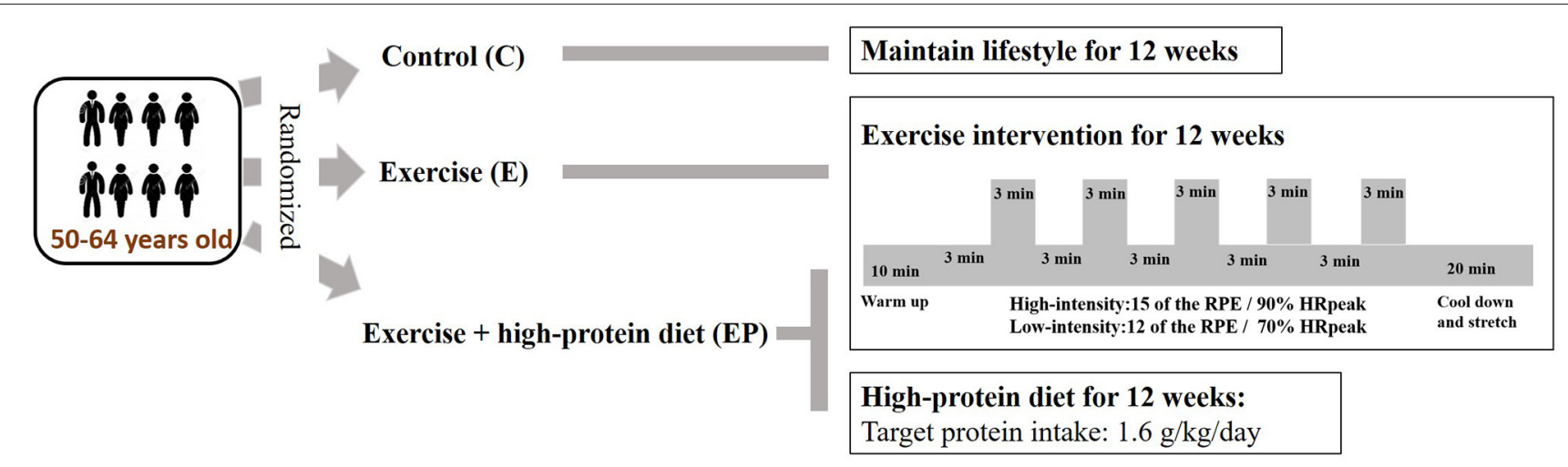

FIGURE 1 | Study design

of protein for adults at $0.8 \mathrm{~g} / \mathrm{kg} /$ day (20). Daily protein intake at $1.6 \mathrm{~g} / \mathrm{kg}$ body weight (BW) was chosen because $1.6 \mathrm{~g} / \mathrm{kg} /$ day of protein intake was shown to protect lean mass in response to exercise- and/or dietary-induced weight loss and to maximize the increase of muscle mass in healthy adults with exercise $(21,22)$. In the current study, whey protein powder supplements (M Power All WHEY plain, BriPower International Enterprise, Taiwan) was provided to participants to help them reach the target daily protein intake because our pilot study found that it was difficult for Asian middle-aged people to achieve $1.6 \mathrm{~g} / \mathrm{kg} /$ day of protein intake with the traditional diet. The whey protein supplementation contained $50 \%$ of essential amino acid and $50 \%$ of non-essential amino acid. It provided $20 \mathrm{~g}$ of branch-chain amino acid (46\% of leucine, $28 \%$ of isoleucine, and $26 \%$ of valine) per $100 \mathrm{~g}$ of protein. The target calorie intake was $25 \mathrm{kcal} / \mathrm{kg}$ body weight (Health Promotion Administration, Ministry of Health, and Welfare, Taiwan). Participants in the EP group were asked to record their daily food and beverage intake and upload the information to an application (Cofit, Cofit Healthcare Inc., Taiwan). A licensed dietitian analyzed the nutritional composition of the dietary intake of participants based on the report that participants uploaded and provided the diet education and consultation for participants. The dietitian also calculated the insufficient protein intake and gave the appropriate amount of protein powder so that participants could reach the target protein intake of the study. At baseline, the average daily energy and protein intakes were not significantly different among groups. Diet intervention increased the protein intake of participants in the EP group to the level of $1.5 \pm 0.05 \mathrm{~g} / \mathrm{kg} / \mathrm{day}$. In addition, individuals in the EP group had greater percentage of energy intake from protein and lower percentage of energy intake from carbohydrate than that in the $\mathrm{C}$ and the E groups (Figure 2).

\section{Outcome Measurement Body Composition}

Body height and body weight were assessed before and after the 12-week intervention. Body composition (fat mass and muscle mass) was assessed by dual-energy X-ray absorptiometry (DXA) (Lunar iDXA, GE Medical System, Madison, WI).

\section{Oral Glucose Tolerance Test}

Oral glucose tolerance test (OGTT) challenges glucose homeostasis and reflects insulin sensitivity and $\beta$-cell function of individuals $(23,24)$. Oral glucose tolerance test was performed on participants without diabetes mellitus (DM) according to the recommendation of the World Health Organization. Specifically, individuals drank $300 \mathrm{ml}$ of water with $75 \mathrm{~g}$ of glucose in $5 \mathrm{~min}$ after overnight fasting. Blood samples were taken at baseline and at 30, 60, and $120 \mathrm{~min}$ after drinking the glucose water. Plasma glucose and serum insulin levels were determined by the hexokinase glucose-6-phosphate dehydrogenase (G-6-PDH) method and the immunoradiometric assay, respectively. The area under curves (AUCs) of glucose and insulin levels at different time points were calculated by the trapezoid method.

The insulin-peak-time was determined as the time point that insulin concentration reached its highest value during the OGTT. The insulin-peak-time reflects the function of beta cells $(25,26)$. In addition, insulin sensitivity index $\mathrm{x}_{0,120}\left(\mathrm{ISI}_{0,120}\right)$ was calculated by the following formula (27):

$$
\begin{aligned}
\mathrm{m} & =[75,000 \mathrm{mg}+(\text { fasting glucose } \\
& -120 \mathrm{~min} \text { glucose }) \times 0.19 \\
& \times \mathrm{BW}] \div 120
\end{aligned}
$$

Mean plasma glucose $(\mathrm{MPG})=$ (fasting glucose

$$
+120 \text { min glucose }) \div 2
$$

Mean serum insulin(MSI) $=\log [$ (fasting insulin

$$
+120 \text { min insulin }) \div 2]
$$

Metabolic clearance rate $(\mathrm{MCR})=\mathrm{m} \div \mathrm{MPG}$

$$
\mathrm{ISI}_{0,120}=\mathrm{MCR} \div \mathrm{MSI}
$$

Insulin sensitivity index $\mathrm{x}_{0,120}$ has been shown to be a valid index of insulin sensitivity in various populations and has been used in many clinical studies (27-29). The higher values of the index indicate the better insulin sensitivity of individuals.

\section{Lipid Profiles}

Participants arrived laboratory at 8:00 a.m. after a 12-h overnight fast and $2 \mathrm{ml}$ of venous blood was collected. Fasting serum 
A

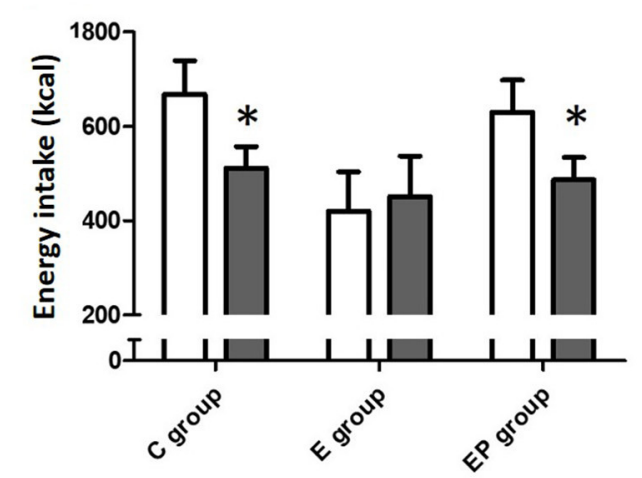

B

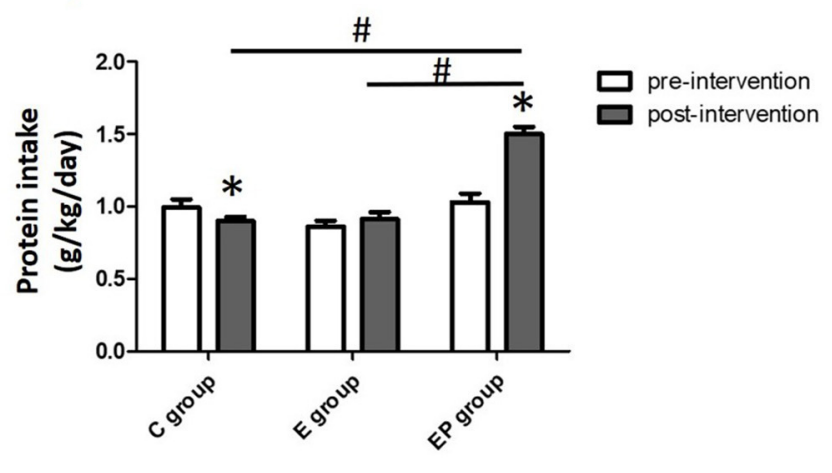

C

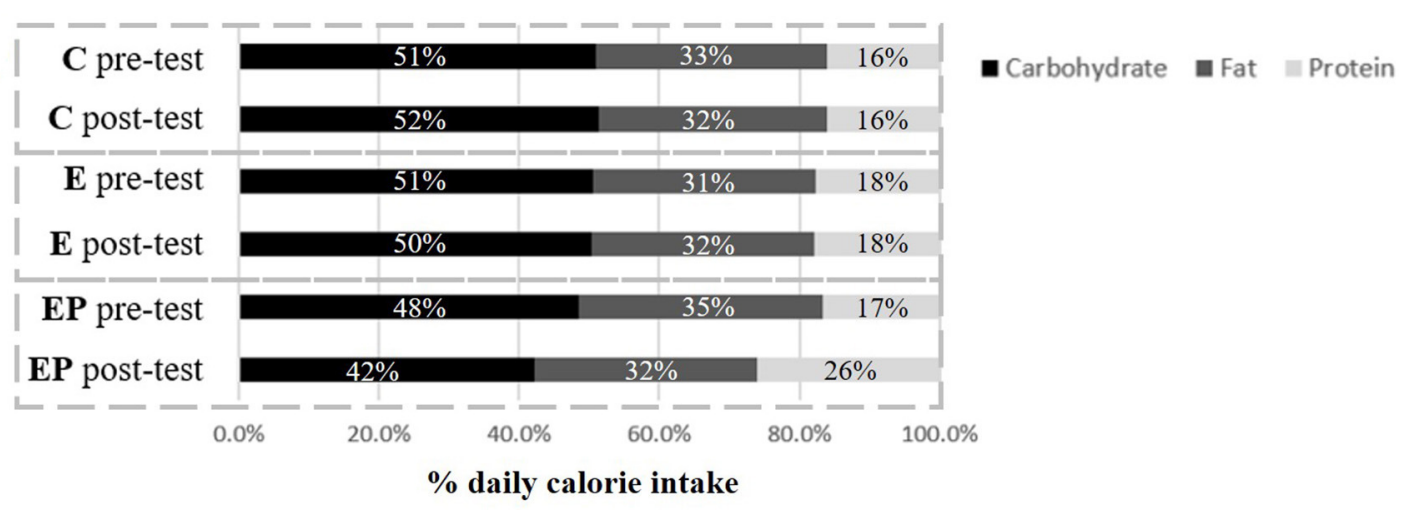

FIGURE 2 | Daily energy intake of participants before and after intervention. (A) Daily energy intake. (B) Daily protein intake. (C) The percentage of macronutrients of daily energy intake. Data were presented as mean \pm SE or percentage. C, control group; E, exercise group; EP, exercise combined with high-protein diet group. *Significant change from the baseline. \# Significantly different between groups.

CHOL, TG, low-density lipoprotein (LDL), and high-density lipoprotein (HDL) were analyzed at baseline and after the 12weeks of intervention. All lipid content measurements were performed by the Beckman Coulter AU5820 (Beckman Coulter, Inc., Brea, CA, USA) with $300 \mu$ l of serum. Each test was performed according to the manufacturer's protocol $(30,31)$. The intra-assay coefficients of variation for TG, CHOL, LDL, and HDL were $<2.9,<2.6,<4.7$, and $<5.0 \%$, respectively. The CHOL to HDL ratio and the LDL to HDL ratio were calculated. Greater risk of cardiovascular diseases/events have been shown to be associated with higher ratio values of $\mathrm{CHOL}$ to $\mathrm{HDL}$ and LDL to $\operatorname{HDL}(32,33)$.

\section{Markers of Inflammation and Oxidative Stress}

Plasma levels of C-reactive proteins were determined by the ELISA-kit (\#378020 from Beckman Coulter, Brea, Calif., USA). Briefly, plasma samples $(50 \mu \mathrm{l})$ were incubated with CRP Latex Reagent and analyzed on AU5820 auto-analyzer (Beckman Coulter, Inc., Brea, CA, USA). The intra-assay coefficients of variation $(\mathrm{CV})$ for $\mathrm{CRP}$ was $<3.0 \%$ (34).

Oxidative stress was determined by the superoxide dismutase activity in red blood cells (SOD-RBC). The RBC were lysed with four-times volumes of ice-cold HPLC-grade deionized water and centrifuge at $10000 \mathrm{~g}$ for $15 \mathrm{~min}$ at $4^{\circ} \mathrm{C}$. The erythrocytes lysate was incubated in an assay medium containing phosphate buffer and the reaction was initiated by adding xanthine oxidase. The activity of SOD was determined spectrophotometrically at a wavelength of $450 \mathrm{~nm}$ for $20 \mathrm{~min}$ at $37^{\circ} \mathrm{C}$. The optical density (OD) was determined by a spectrophotometer (Tecan, Männedorf, Switzerland) (35).

\section{Statistical Analysis}

Data were presented as mean \pm standard error (SE). All outcome variables were tested for normal distribution by the Shapiro-Wilk test. Fasting insulin concentration, TG, LDL to HDL ratio, CHOL to HDL ratio, and CRP were log-transformed before the statistical analysis because data were not normally distributed. Differences in baseline characteristics among groups were determined by one-way analysis of variance (ANOVA) for continuous variables and by the chi-square test for categorical variables. Treatment effects were determined by analysis of covariance (ANCOVA) with baseline values as covariates. The Bonferroni test was used as the post-hoc test. Within-group comparisons were performed with paired $t$-test. An intention to treat analysis was used in this study where missing data were inputted with pre-test values based on the last-observation-carried-forward technique. Pearson's correlation coefficients were used to determine the relationship between daily protein intake and outcome variables. 
TABLE 1 | Effects of interventions on anthropometry and body composition.

\begin{tabular}{|c|c|c|c|c|c|c|}
\hline & \multicolumn{2}{|c|}{ C $(n=23 ;$ Male $=2$, Female $=21)$} & \multicolumn{2}{|c|}{$E(n=23 ;$ Male $=3$, Female $=20)$} & \multicolumn{2}{|c|}{$\mathrm{EP}(n=23 ;$ Male $=1$, Female $=22)$} \\
\hline & Pre & Post & Pre & Post & Pre & Post \\
\hline \multicolumn{7}{|l|}{ Anthropometry } \\
\hline Body height (cm) & \multicolumn{2}{|c|}{$157.4 \pm 1.3$} & \multicolumn{2}{|c|}{$159.6 \pm 1.9$} & \multicolumn{2}{|c|}{$156.9 \pm 1.3$} \\
\hline Male & \multicolumn{2}{|c|}{$168.8 \pm 5.8$} & \multicolumn{2}{|c|}{$173.5 \pm 0.5$} & \multicolumn{2}{|c|}{$170 \pm 0.0$} \\
\hline Female & \multicolumn{2}{|c|}{$156.4 \pm 1.1$} & \multicolumn{2}{|c|}{$157.5 \pm 1.7$} & \multicolumn{2}{|c|}{$156.1 \pm 1.3$} \\
\hline $\mathrm{BW}(\mathrm{kg})$ & $68.7 \pm 2.2$ & $68.4 \pm 2.2$ & $71.8 \pm 2.5$ & $71.0 \pm 2.5$ & $67.1 \pm 2.3$ & $66.0 \pm 2.1^{\star}$ \\
\hline Male & $85.9 \pm 11.6$ & $83 \pm 7.8$ & $91.8 \pm 4.7$ & $91.4 \pm 5.0$ & $71.3 \pm 0.0$ & $68.5 \pm 0.0$ \\
\hline Female & $67.1 \pm 1.9$ & $67.0 \pm 2.1$ & $68.8 \pm 2.1$ & $68.0 \pm 2.0$ & $66.9 \pm 2.4$ & $65.9 \pm 2.2$ \\
\hline BMl $\left(k g / m^{2}\right)$ & $27.6 \pm 0.7$ & $27.5 \pm 0.7$ & $28.1 \pm 0.7$ & $27.8 \pm 0.7$ & $27.3 \pm 0.9$ & $26.8 \pm 0.8^{\star}$ \\
\hline Male & $30.0 \pm 2.0$ & $29.1 \pm 0.8$ & $30.5 \pm 1.6$ & $30.4 \pm 1.7$ & $24.7 \pm 0.0$ & $23.7 \pm 0.0$ \\
\hline Female & $27.4 \pm 0.7$ & $27.4 \pm 0.8$ & $27.7 \pm 0.7$ & $27.4 \pm 0.7$ & $27.4 \pm 0.9$ & $27.0 \pm 0.8$ \\
\hline Percentage body fat (\%) & $41.7 \pm 1.0$ & $40.9 \pm 1.0$ & $42.7 \pm 1.2$ & $42.0 \pm 1.1$ & $40.3 \pm 0.9$ & $39.9 \pm 1.1$ \\
\hline Male & $32.6 \pm 0.3$ & $30.7 \pm 1.3$ & $33.3 \pm 2.1$ & $33.2 \pm 2.0$ & $31.2 \pm 0.0$ & $27.6 \pm 0.0$ \\
\hline Female & $42.6 \pm 0.9$ & $41.9 \pm 0.8^{\star}$ & $44.1 \pm 1.0$ & $43.3 \pm 1.0^{*}$ & $40.8 \pm 0.9$ & $40.5 \pm 1.0$ \\
\hline \multicolumn{7}{|l|}{ Body composition } \\
\hline AFM (kg) & $2.4 \pm 0.1$ & $2.4 \pm 0.1$ & $2.6 \pm 0.1$ & $2.5 \pm 0.1^{\star}$ & $2.3 \pm 0.1$ & $2.2 \pm 0.1^{*}$ \\
\hline Male & $2.8 \pm 0.4$ & $2.4 \pm 0.0$ & $3.1 \pm 0.4$ & $3.0 \pm 0.4$ & $2.3 \pm 0.0$ & $1.8 \pm 0.0$ \\
\hline Female & $2.4 \pm 0.1$ & $2.4 \pm 0.1$ & $2.6 \pm 0.2$ & $2.5 \pm 0.1^{\#}$ & $2.4 \pm 0.2$ & $2.3 \pm 0.1^{*}$ \\
\hline TBF (kg) & $27.7 \pm 1.1$ & $27.2 \pm 1.1$ & $29.8 \pm 1.3$ & $28.9 \pm 1.2^{*}$ & $26.6 \pm 1.4$ & $25.8 \pm 1.4^{\star}$ \\
\hline Male & $27.0 \pm 3.6$ & $24.4 \pm 0.1$ & $29.7 \pm 2.8$ & $29.4 \pm 2.9$ & $21.4 \pm 0.0$ & $18.2 \pm 0.0$ \\
\hline Female & $27.8 \pm 1.1$ & $27.5 \pm 1.2$ & $29.8 \pm 1.4$ & $28.8 \pm 1.4^{*}$ & $26.8 \pm 1.4$ & $26.1 \pm 1.4^{\star}$ \\
\hline ASM (kg) & $16.8 \pm 0.8$ & $17.0 \pm 0.7$ & $17.4 \pm 1.0$ & $17.4 \pm 1.0$ & $16.7 \pm 0.6$ & $16.6 \pm 0.6$ \\
\hline Male & $26.0 \pm 4.0$ & $25.5 \pm 3.1$ & $27.8 \pm 0.8$ & $27.5 \pm 1.1$ & $22.4 \pm 0.0$ & $22.5 \pm 0.0$ \\
\hline Female & $15.9 \pm 0.5$ & $16.2 \pm 0.5$ & $15.9 \pm 0.5$ & $15.9 \pm 0.5$ & $16.4 \pm 0.6$ & $16.3 \pm 0.6$ \\
\hline TSM (kg) & $38.9 \pm 1.6$ & $39.2 \pm 1.5$ & $40.0 \pm 1.8$ & $40.1 \pm 1.8$ & $38.8 \pm 1.3$ & $38.3 \pm 1.2$ \\
\hline Male & $55.9 \pm 8.2$ & $55.6 \pm 6.5$ & $59.1 \pm 2.9$ & $59.0 \pm 3.0$ & $47.1 \pm 0.0$ & $47.6 \pm 0.0$ \\
\hline Female & $37.3 \pm 1.1$ & $37.6 \pm 1.1$ & $37.2 \pm 0.9$ & $37.3 \pm 0.9$ & $38.4 \pm 1.2$ & $37.9 \pm 1.1$ \\
\hline
\end{tabular}

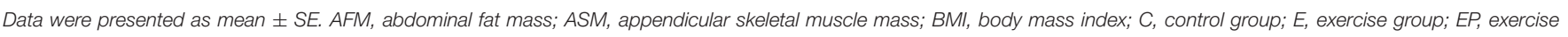
combined with high-protein diet group; TBF, total body fat mass; TSM, total skeletal muscle mass.

*Significant change from the baseline.

${ }^{\#} A$ trend to change significantly from the baseline $(0.1>p \geq 0.05)$.

The $G^{*}$ power was used to calculate the needed sample size and 22 participants were required for each group with a statistical power of 0.95 , effects size of 0.25 , and alpha value of 0.05 . The significance level was set at $p<0.05$. SPSS 24.0 (Statistical Package for the Social Sciences, SPSS, Chicago, USA) was used to perform statistical analyses.

\section{RESULTS}

\section{Basic Characteristics of Participants}

Overall, the average fasting glucose, fasting insulin, and ISI $_{0,120}$ of all participants was $94.2 \pm 1.3 \mathrm{mg} / \mathrm{dl}, 13.4 \pm 0.9 \mu \mathrm{IU} / \mathrm{ml}$, and $19.9 \pm 1.2$, respectively. The average CHOL, TG, HDL, and LDL of all participants was $201.8 \pm 4.2,111.8 \pm 7.8,55.2 \pm 1.4$, and $123.0 \pm 4.1 \mathrm{mg} / \mathrm{dl}$, respectively. The average CRP and SOD-RBC of all participants was $0.22 \pm 0.02 \mathrm{mg} / \mathrm{dl}$ and $94.1 \pm 1.3 \mathrm{U} / \mathrm{mg}-$ protein. Baseline characteristics related to body composition, glucose homeostasis, lipid profiles, systematic inflammation, and oxidative stress were similar among groups, except for the 2-h glucose of OGTT. Two-hour glucose of OGTT in the E group was lower than that in the EP group $(p<0.05)$.

\section{Effects of Interventions on Body Composition}

Obesity is the main risk factor of metabolic and cardiovascular diseases (2). All parameters including BW, BMI, abdominal fat mass (AFM), total body fat mass (TBF), appendicular skeletal muscle mass (ASM), and total skeletal muscle mass (TSM) were similar among groups after intervention $(p>0.05)$. Within-group comparisons showed that all parameters of body composition did not change in the $\mathrm{C}$ group from the pre-test to the post-test. After the intervention, the average BW decreased $1.6 \%$ in the EP group; the average BMI decreased from $1.6 \%$ in the EP group; AFM decreased 3.6 and $3.7 \%$ in the E and EP groups, respectively $(p<0.05)$; TBF decreased 2.8 and $3.0 \%$ in the E and EP groups, respectively $(p<0.05)$. The changes of skeletal muscle mass before and after the intervention were not significant in all groups (Table $\mathbf{1}$ and Figure 3). 


\section{Effects of Interventions on Glucose Homeostasis}

Glucose homeostasis is a key marker of cardiometabolic health of individuals (36). We found that fasting glucose levels, fasting insulin levels, and AUCs of glucose and insulin were similar among groups after intervention $(p>0.05)$. Within-group comparisons showed that the 2-h glucose of OGTT decreased $10 \%$ in the EP group after intervention $(p<0.05)$, but the values did not change in the $\mathrm{C}$ and $\mathrm{E}$ groups after intervention $(p>0.1)$. The $\mathrm{ISI}_{0,120}$ increased $11.5 \%$ in the EP group and had a trend to increase in the E group $(p=0.052)$ (Table 2). Regarding the insulin-peak-time, the percentages of individuals having insulin-peak-time at 30,60, or $120 \mathrm{~min}$ of OGTT were different among groups after intervention $(p=0.031)$. In the E group, the percentage of individuals having insulin-peak-time at $30 \mathrm{~min}$ increased from 25 to $50 \%$, and the percentage of individuals having insulin-peak-time at $120 \mathrm{~min}$ decreased from

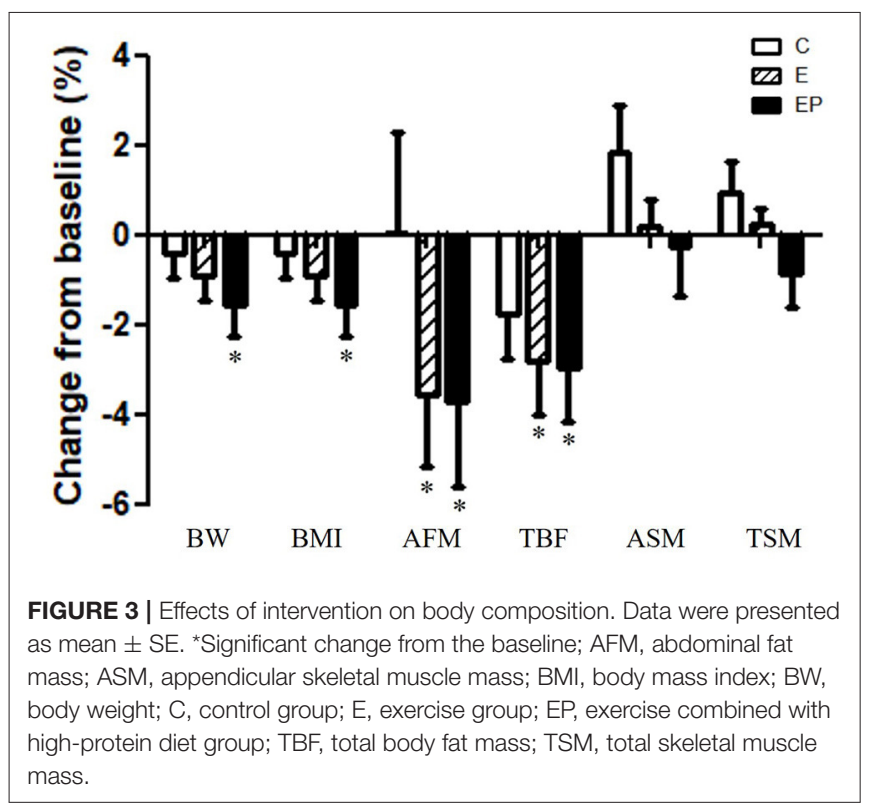

37.5 to $12.5 \%$ after the intervention. The pattern of insulin-peaktime did not change in the $\mathrm{C}$ and EP groups (Figure 4).

\section{Effects of Interventions on Lipid Profiles, Systemic Inflammation, and Oxidative Stress}

Dyslipidemia predicts the CVD risk $(5,10)$. After 12 weeks of intervention, the CHOL and TG of the EP group were significantly lower than that of the $\mathrm{C}$ group $(p<0.05)$. The CHOL in the EP group decreased from $204.1 \pm 9.4$ to $190.2 \pm 10.7 \mathrm{mg} / \mathrm{dl}$ and it did not change in the $\mathrm{C}$ and $\mathrm{E}$ groups. The TG value in the $\mathrm{C}$ group increased from $101.2 \pm 10.9$ to $119.0 \pm 10.3 \mathrm{mg} / \mathrm{dl}$; whereas, it decreased from $132.4 \pm 17.9$ to $125.9 \pm 17.6 \mathrm{mg} / \mathrm{dl}$ in the EP group. There were no group differences in HDL, LDL, the LDL to HDL ratio, and the CHOL to HDL ratio. Withingroup comparisons showed that the HDL level decreased after intervention in the EP group (from $55.8 \pm 2.8$ to $51.1 \pm 2.5$ $\mathrm{mg} / \mathrm{dl}$ ) (Figure 5).

Inflammation and oxidative stress are associated with insulin resistance and vascular dysfunction (37). We found that CRP in the EP group decreased significantly $(p=0.008)$ from $0.22 \pm$ 0.04 to $0.16 \pm 0.03 \mathrm{mg} / \mathrm{dl}$. The CRP values in the $\mathrm{C}$ and $\mathrm{E}$ group did not change significantly. The pre-test and post-test values of the CRP in the C group were $0.18 \pm 0.04$ and $0.19 \pm 0.03$, respectively. The pre-test and post-test values of the CRP in the E group were $0.25 \pm 0.04$ and $0.23 \pm 0.04$, respectively. In terms of antioxidant SOD-RBC, the level of SOD-RBC in the E group showed a tendency to increase $(p=0.057)$ after intervention. The levels of SOD-RBC in the C and EP group did not change significantly (Figure 6).

\section{Correlation Between Daily Protein Intake and Outcome Measurements}

We found that daily protein intake during the intervention was negatively correlated with BW $(r=-0.294 ; p=0.015)$, BMI $(r=-0.252 ; p=0.038)$, TBF $(r=-0.351 ; p=0.003)$ and AFM $(r=-0.362 ; p=0.002)$ at post-test. There were no significant correlations between daily protein intake and parameters of glucose homeostasis, lipid profiles, and CRP.

TABLE 2 | Effects of interventions on variables derived from oral glucose tolerance test.

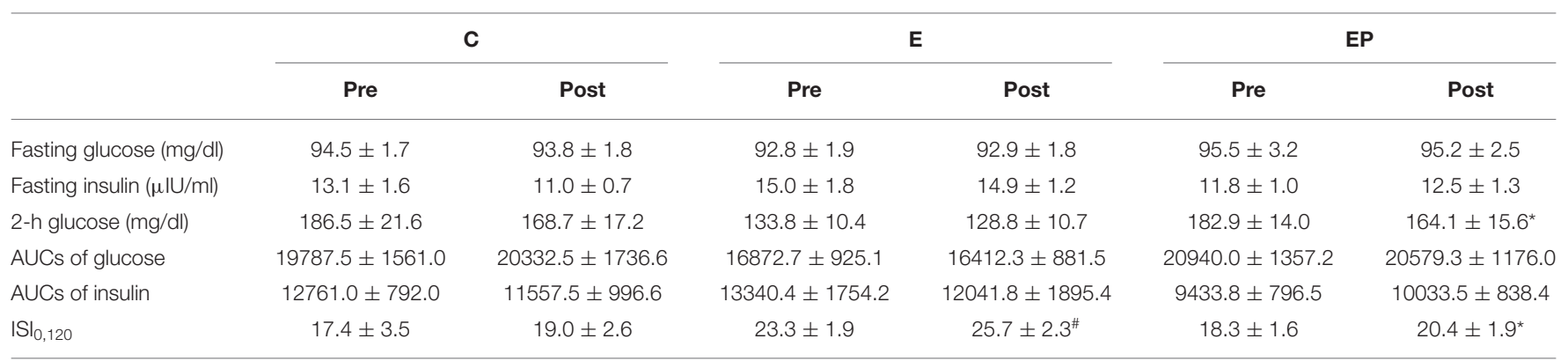

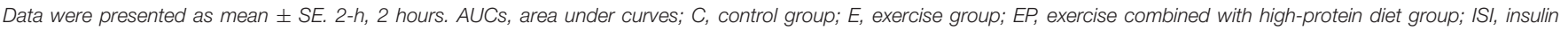
sensitivity index.

*Significant change from the baseline.

\#A trend to change significantly from the baseline $(0.1>p \geq 0.05)$. 


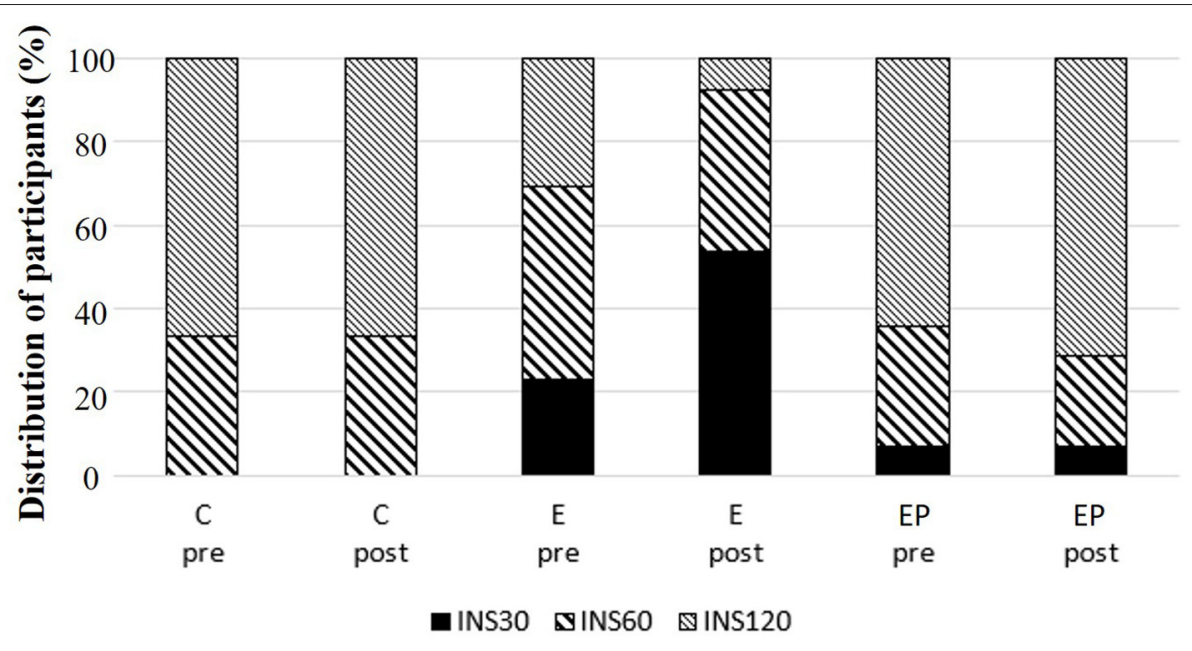

FIGURE 4 | Distribution of insulin-peak-time during oral glucose tolerance test (OGTT) among groups. C, control group; E, exercise group; EP, exercise combined with high-protein diet group. INS30: peak insulin level at 30 min of OGT. INS60: peak insulin level at 60 min of OGTT. INS120: peak insulin level at 120 min of OGTT.

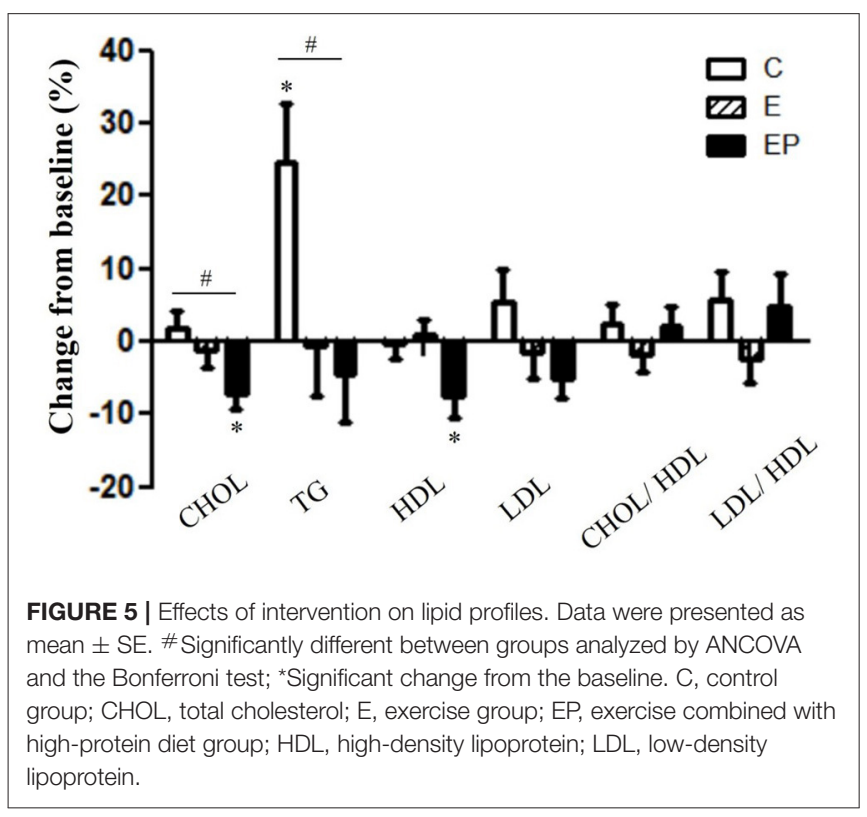

\section{DISCUSSION}

This study examined the effects of exercise alone or in combination with high-protein diet on biomarkers of cardiometabolic health in middle-aged obese adults. The main finding is that exercise combined with high-protein diet significantly improved insulin sensitivity (IS) and decreased 2-h glucose of OGTT, CHOL, TG, and CRP levels in middleaged obese adults. Exercise alone improved $\beta$-cell function characterized by the insulin-peak-time during the OGTT. Last, exercise reduced the fat mass of middle-aged obese adults with or without high-protein diet.

Appropriate insulin secretion and IS maintain the glucose homeostasis of individuals. In the current study, we found that
IS improved significantly in the EP group and had a trend to improve in the E group. In addition, glucose levels at $2 \mathrm{~h}$ of the OGTT decreased $10.3 \%$ in the EP group after the intervention but the change in the E group was not significant. Both exercise and high-protein diet have been shown to improve the IS of individuals with obesity $(17,28,38)$. However, mechanisms underlying the beneficial effects of exercise and high-protein diet on IS of obese individuals are different. Exercise increases IS by muscle contraction-induced increase of cellular glucose transporters (39). In contrast, high-protein diets increase IS via loss of body weight and insulinotropic effects of dietary protein $(14,40)$. Consistent with previous reports, we found daily energy intake decreased in our participants within the EP group. The BW and BMI also decreased significantly in the EP group. Our finding, the negative correlation between the daily protein intake and BW, BMI, TBF, and AFM, further supports the role of high-protein diet on loss of body weight. The high-protein diet associated greater satiety and reductions in appetite are likely the underlying mechanisms contributing to the reduced energy intake of participants in the EP group $(14,15)$. Thus, our findings together with others suggest that individuals can take advantage of the specificity of exercise and high-protein diet on the IS pathway to achieve the best outcomes of IS and metabolic health.

To our knowledge, this is the first study examining the effects of exercise and diet on the insulin-peak-time during the OGTT at the same time. Insulin-peak-time during the OGTT reflects $\beta$-cell function of individuals $(9,26,41,42)$. Impairment of early-phase insulin release suggests defects of insulin secretion in response to glucose. The delayed and blunted early-phase insulin response to glucose results in reduced suppression of hepatic glucose production and insufficient muscle glucose uptake (43). Praveen et al. (44) reported that individuals (with normal glucose tolerance) whose insulin-peak-time was at $60 \mathrm{~min}$ and at $120 \mathrm{~min}$ during OGTT had higher postprandial glucose levels than individuals whose insulin-peak-time was at $30 \mathrm{~min}$. Sun et al. (25) followed individuals (with normal glucose tolerance 

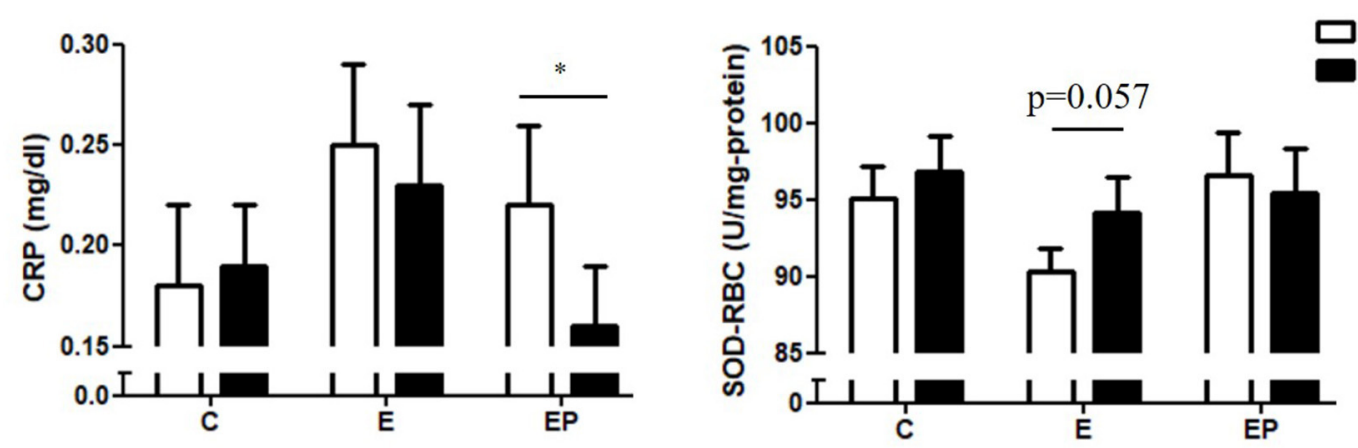

FIGURE 6 | Effects of intervention on inflammatory and oxidative stress markers. Data were presented as mean \pm SE. C, control group; CRP, C-reactive protein; E, exercise group; EP, exercise combined with high-protein diet group; SOD-RBC, superoxide dismutase activity in red blood cells. ${ }^{\star} p<0.05$.

at baseline) over a 6 years period and found that individuals with delayed insulin-peak-time during OGTT at baseline (120 and $180 \mathrm{~min}$ ) were at a greater risk (7.3 times) for diabetes incidence compared to individuals with shorter insulin-peaktime (30 $\mathrm{min}$ ) at baseline. In the current study where women were the majority (91\%), we found that the number of participants having insulin peak at $30 \mathrm{~min}$ during the OGTT doubled in the $\mathrm{E}$ group after intervention. The beneficial effects of exercise on $\beta$-cell function were also reported in healthy men and men with pre-diabetes or T2DM (45). Although, clear mechanistic details of this phenomenon are still not understood, exercise-associated decreases of pancreatic fat are suggested as a mechanism underlying the exercise-induced benefits on $\beta$-cell function (45).

We did not see changes in the pattern of insulin-peak-time during OGTT in the EP group. This finding is unexpected. The non-significant change is likely due to a trend of poorer baseline glucose tolerance in participants of the EP group than that in the E group $(p=0.057)$. Supporting this explanation, Heiskanen et al. (45) demonstrated that exercise training increased earlyphase insulin secretion rate in healthy men but not in prediabetic/T2DM men. Another possible explanation for the nonsignificant change of the insulin-peak-time during OGTT in the EP group is the protein source. Kahleova et al. (46) found that with matched energy and macronutrient composition, a meal with plant-based protein induced greater rate sensitivity (insulin secretion rate in response to the change of glucose) than a meal with meat-based protein in men with T2DM. Since the source of protein was not investigated and controlled in this study, the non-beneficial effects of exercise on insulin-peak-time during the OGTT in the EP group could be due to the increased intake of meat. Further, studies are needed to test the hypothesis.

We found that lipid profile did not significantly change in the $\mathrm{E}$ group, but $\mathrm{CHOL}$ and $\mathrm{TG}$ significantly reduced in the EP group. Triglyceride values have been shown to have a moderate and high association with coronary heart diseases (47). A meta-analysis of 160 randomized controlled trials (7,487 participants) showed that while exercise improved lipid profiles, the effects were gender-specific and dependent on the health condition of individuals (38). Greater exercise-related improvement in lipid profiles was reported in men than in women and in individuals with at least one health condition (T2DM, hypertension, hyperlipidemia, and metabolic syndrome) than individuals with no health condition stated above. Thus, there are two possible contributing factors to the non-significant change in lipid profile of the E group: (1) the composition of the study participants was $91 \%$ women, and (2) $61 \%$ of participants did not present with any of the identified health conditions stated above.

The decrease in TG level with high-protein diet is observed across many studies, including the current study. For instance, a meta-analysis of randomized controlled trials found that 12 weeks of high-protein diets (average protein intake: 1.3 $\mathrm{g} / \mathrm{kg} / \mathrm{day}$; the average percentage calorie intake from protein: $30 \%$ ) provided more favorable changes in TG than iso-calorically standard-protein diets (average protein intake: $0.7 \mathrm{~g} / \mathrm{kg} /$ day; the average percentage calorie intake from protein: 18\%) in overweight/obese adults (48). The mechanism underlying the decrease of TG with high-protein diets is likely due to the reduction of the intake of carbohydrates $(\mathrm{CHO})$. In fact, it was shown that when the $\mathrm{CHO}$ intake accounts for more than $50 \%$ of total calorie intake, there is an elevation in blood TG level (49). Supporting the link between CHO intake and TG level, we demonstrated that the percentage of calorie intake from $\mathrm{CHO}$ in the EP group (42\%) was significantly lower than that in the C (52\%) and E group (50\%). Similarly, in the meta-analysis study by Wycherley, the percentages of calorie intake from $\mathrm{CHO}$ in the high-protein-diets group and the iso-calorically standardprotein-diets group were 42 and 57\% respectively (48). Thus, our findings together with others suggest that high-protein diet associated reduced $\mathrm{CHO}$ intake contributes to the reduction of TG levels.

Interestingly, we found HDL did not change in the E group and it decreased in the EP group after intervention. Most studies demonstrated an increase in HDL after exercise training (38, 5052). A meta-analysis showed that aerobic exercise training with an average duration of 22 weeks significantly increased HDL level in women (50). Thus, the relatively short intervention period (12 weeks) might be a reason why we did not find the increase of HDL after exercise training. Another possible reason for the non-significant effects of exercise on HDL is that participants 
in this study had normal HDL levels at baseline $(55.2 \mathrm{mg} / \mathrm{dl})$. Most studies that found significant increase of HDL with exercise training had subjects with metabolic syndrome or low baseline HDL levels $(53,54)$. Similar to our finding, Keating et al. (55), showed that exercise training did not increase HDL in adults with normal HDL levels. It is unclear why HDL levels decreased significantly in the EP group, but it could be associated with the changes of HDL subpopulation profile. It was shown that large HDL particles are related with lower CVD risk, whereas, medium and small HDL particles are related with greater CVD risk $(56,57)$. Thus, further research that analyzes the HDL subpopulation profile is needed to clarify the effects of combined high-protein diet and exercise intervention on middle-aged obese adults. Importantly, although, we found HDL decreased in the EP group after intervention, the CHOL to HDL ratio and the LDL to HDL ratio (two better predictors for CVD morbidity than HDL alone) $(32,58,59)$ did not change. This finding suggests that combined high-protein diet and exercise intervention does not increase the CVD risk.

We found that only exercise combined with high-protein diet decreased CRP of middle-aged obese adults; exercise alone did not significantly decrease CRP in this population. To date, the effects of exercise on inflammation are still inconclusive. A meta-analysis showed beneficial effects of exercise on the inflammatory status (CRP and interleukin$6)$ in adults with obesity (60). In contrast, another metaanalysis showed that exercise (both moderate- and vigorousintensity) did not improve inflammatory status (CRP, tumor necrosis factor-alpha and interleukin-6) of sedentary healthy adults (38). Previous studies indicated that the decrease of systemic inflammation is associated with the degree of weight loss such that the more weight loss, the more decrease of systemic inflammation (61-63). Thus, the significant decrease of CRP in the EP group but not in the E group is likely associated with greater loss of BW in the EP group. Regarding the important role of the systemic inflammation in the cardiometabolic health, our finding implies that middle-aged obese adults could be suggested to have a high-protein diet in addition to exercise to help loss weight and improve the cardiometabolic health.

Some limitations exist in this study. First, we did not record the source of protein (plant or animal), thus, findings of this study can only suggest levels of daily protein intake. Second, only one oxidative stress marker was evaluated. A more comprehensive assessment including levels of multiple antioxidant enzymes (RBC-SOD, catalase, and glutathione

\section{REFERENCES}

1. Abdullah A, Amin F, Stoelwinder J, Tanamas S, Wolfe R, Barendregt J, et al. Estimating the risk of cardiovascular disease using an obeseyears metric. BMJ Open. (2014) 4:e005629. doi: 10.1136/bmjopen-2014005629

2. Nie J, Ardern C. Association between obesity and cardiometabolic health risk in Asian-Canadian sub-groups. PLoS ONE. (2014) 9:e107548. doi: 10.1371/journal.pone.0107548 peroxidase), free radical levels, and oxidative damage markers (such as serum malondialdehyde) is needed to provide solid evidence about the effects of intervention on oxidative stress of middle-aged obese adults. In summary, exercise combined with high-protein diet, but not exercise alone, improved IS, glucose tolerance, lipid profiles, and inflammation status in middle-aged obese adults. Thus, high-protein diet can be suggested to middle-aged obese adults who exercise to enhance cardiometabolic health.

\section{DATA AVAILABILITY STATEMENT}

The raw data supporting the conclusions of this article will be made available by the authors, without undue reservation.

\section{ETHICS STATEMENT}

The studies involving human participants were reviewed and approved by Institutional Review Board of the National Yang-Ming University. The patients/participants provided their written informed consent to participate in this study.

\section{AUTHOR CONTRIBUTIONS}

C-NC and K-YC conceptualized the study, analyzed and interpreted the data, and wrote the manuscript. C-NC and $\mathrm{K}-\mathrm{JH}$ coordinated and managed the project. K-JH and J-JC performed the intervention and collected the data. All authors reviewed and approved the manuscript.

\section{FUNDING}

This study was supported by the Ministry of Science and Technology, Taiwan [Grant Nos: MOST-106-2314-B-010-052 -MY3 (C-NC); MOST-109-2314-B-010-036-MY3 (C-NC)] and partly supported by the University of Taipei for providing the DXA examination.

\section{ACKNOWLEDGMENTS}

We thank Shiow-Chwen Tsai for performing the DXA examination and helping data interpretation. We also thank the help of dietitian Ying-Fang Wang and Yun-Ru Chen in the diet intervention and Hua-Hung Yuan in the exercise intervention of this study. Last, we would like to thank all the individuals who volunteered to participate this study. 
6. Sanghera DK, Bejar C, Sharma S, Gupta R, Blackett PR. Obesity genetics and cardiometabolic health: potential for risk prediction. Diabetes Obes Metab. (2019) 21:1088-100. doi: 10.1111/dom.13641

7. Pouliot M-C, Després J-P, Nadeau A, Moorjani S, Prud'homme D, Lupien PJ, et al. Visceral obesity in men: associations with glucose tolerance, plasma insulin, lipoprotein levels. Diabetes. (1992) 41:82634. doi: $10.2337 /$ diabetes.41.7.826

8. Monteiro R, Azevedo I. Chronic inflammation in obesity and the metabolic syndrome. Mediators Inflamm. (2010) 2010:289645. doi: 10.1155/2010/289645

9. Ying W, Lee YS, Dong Y, Seidman JS, Yang M, Isaac R, et al. Expansion of islet-resident macrophages leads to inflammation affecting beta cell proliferation and function in obesity. Cell Metab. (2019) 29:457-474 e455. doi: 10.1016/j.cmet.2018.12.003

10. Ridker PM, Hennekens $\mathrm{CH}$, Buring JE, Rifai N. C-reactive protein and other markers of inflammation in the prediction of cardiovascular disease in women. $N$ Engl J Med. (2000) 342:836-43. doi: 10.1056/NEJM200003233421202

11. Ross R, Hudson R, Stotz PJ, Lam M. Effects of exercise amount and intensity on abdominal obesity and glucose tolerance in obese adults: a randomized trial. Ann Intern Med. (2015) 162:325-34. doi: 10.7326/M14-1189

12. Marson EC, Delevatti RS, Prado AK, Netto N, Kruel LF. Effects of aerobic, resistance, and combined exercise training on insulin resistance markers in overweight or obese children and adolescents: a systematic review and meta-analysis. Prev Med. (2016) 93:211-8. doi: 10.1016/j.ypmed.2016.10.020

13. Sogaard D, Lund MT, Scheuer CM, Dehlbaek MS, Dideriksen SG, Abildskov $\mathrm{CV}$, et al. High-intensity interval training improves insulin sensitivity in older individuals. Acta Physiol. (2018) 222:e13009. doi: 10.1111/apha. 13009

14. Weigle DS, Breen PA, Matthys CC, Callahan HS, Meeuws KE, Burden VR, et al. A high-protein diet induces sustained reductions in appetite, ad libitum caloric intake, and body weight despite compensatory changes in diurnal plasma leptin and ghrelin concentrations. Am J Clin Nutr. (2005) 82:418. doi: 10.1093/ajcn/82.1.41

15. Westerterp-Plantenga MS, Lemmens SG, Westerterp KR. Dietary protein - its role in satiety, energetics, weight loss and health. Br J Nutr. (2012) 108(Suppl. 2):S105-112. doi: 10.1017/S0007114512002589

16. Dong JY, Zhang ZL, Wang PY, Qin LQ. Effects of high-protein diets on body weight, glycaemic control, blood lipids and blood pressure in type 2 diabetes: meta-analysis of randomised controlled trials. Br J Nutr. (2013) 110:781-9. doi: 10.1017/S0007114513002055

17. Yu Z, Nan F, Wang LY, Jiang H, Chen W, Jiang Y. Effects of high-protein diet on glycemic control, insulin resistance and blood pressure in type 2 diabetes: a systematic review and meta-analysis of randomized controlled trials. Clin Nutr. (2020) 39:1724-34. doi: 10.1016/j.clnu.2019.08.008

18. Liao CD, Tsauo JY, Wu YT, Cheng CP, Chen HC, Huang YC, et al. Effects of protein supplementation combined with resistance exercise on body composition and physical function in older adults: a systematic review and meta-analysis. Am J Clin Nutr. (2017) 106:1078-91. doi: 10.3945/ajcn.116.143594

19. Hsu KJ, Chien KY, Tsai SC, Tsai YS, Liao YH, Chen JJ, et al. Effects of exercise alone or in combination with high-protein diet on muscle function, aerobic capacity, and physical function in middle-aged obese adults: a randomized controlled trial. J Nutr Health Aging. (2021) 25:72734. doi: 10.1007/s12603-021-1599-1

20. Joint WHO/FAO/UNU Expert Consultation. Protein and amino acid requirements in human nutrition. World Health Organ Tech Rep Ser. (2007) 2007:1-265.

21. Pasiakos SM, Cao JJ, Margolis LM, Sauter ER, Whigham LD, Mcclung JP, et al. Effects of high-protein diets on fat-free mass muscle protein synthesis following weight loss: a randomized controlled trial. FASEB J. (2013) 27:383747. doi: 10.1096/fj.13-230227

22. Morton RW, Murphy KT, Mckellar SR, Schoenfeld BJ, Henselmans M, Helms E, et al. A systematic review, meta-analysis and meta-regression of the effect of protein supplementation on resistance training-induced gains in muscle mass and strength in healthy adults. Br J Sports Med. (2018) 52:376-84. doi: 10.1136/bjsports-2017-097608

23. Stumvoll M, Mitrakou A, Pimenta W, Jenssen T, Yki-Järvinen H, Van Haeften $\mathrm{T}$, et al. Use of the oral glucose tolerance test to assess insulin release and insulin sensitivity. Diabetes Care. (2000) 23:295301. doi: 10.2337/diacare.23.3.295

24. Stumvoll M, Fritsche A, Häring $H$. The OGTT as test for beta cell function? Eur J Clin Invest. (2001) 31:380-1. doi: 10.1046/j.1365-2362.2001.00828.x

25. Sun Y, Han J, Lin Z, Song L, Wang C, Jia W. Delayed insulin secretion response during an OGTT is associated with an increased risk for incidence of diabetes in NGT subjects. J Diabetes Complicat. (2016) 30:153743. doi: 10.1016/j.jdiacomp.2016.07.029

26. Kim JY, Tfayli H, Bacha F, Lee S, Michaliszyn SF, Yousuf S, et al. Betacell function, incretin response, and insulin sensitivity of glucose and fat metabolism in obese youth: relationship to OGTT-time-to-glucose-peak. Pediatr Diabetes. (2020) 21:18-27. doi: 10.1111/pedi.12940

27. Gutt M, Davis CL, Spitzer SB, Llabre MM, Kumar M, Czarnecki EM, et al. Validation of the insulin sensitivity index (ISI $(0,120))$ : comparison with other measures. Diabetes Res Clin Pract. (2000) 47:177-84. doi: 10.1016/S0168-8227(99)00116-3

28. Cederholm J, Wibell L. Insulin release and peripheral sensitivity at the oral glucose tolerance test. Diabetes Res Clin Pract. (1990) 10:16775. doi: 10.1016/0168-8227(90)90040-Z

29. Hwu CM, Hsiao CF, Grove J, Hung YJ, Chuang LM, Chen YT, et al. Surrogate estimates of insulin sensitivity in subjects with hypertension. J Hum Hypertens. (2007) 21:246-52. doi: 10.1038/sj.jhh.1002137

30. Sung YC, Liao YH, Chen CY, Chen YL, Chou CC. Acute changes in blood lipid profiles and metabolic risk factors in collegiate elite taekwondo athletes after short-term de-training: a prospective insight for athletic health management. Lipids Health Dis. (2017) 16:143. doi: 10.1186/s12944-017-0534-2

31. Chmurzynska A, Muzsik A, Krzyzanowska-Jankowska P, Walkowiak J, Bajerska J. The effect of habitual fat intake, IL6 polymorphism, and different diet strategies on inflammation in postmenopausal women with central obesity. Nutrients. (2019) 11:1557. doi: 10.3390/nu11071557

32. Kinosian B, Glick H, Garland G. Cholesterol and coronary heart disease: predicting risks by levels and ratios. Ann Intern Med. (1994) 121:6417. doi: 10.7326/0003-4819-121-9-199411010-00002

33. Kunutsor SK, Zaccardi F, Karppi J, Kurl S, Laukkanen JA. Is high serum LDL/HDL cholesterol ratio an emerging risk factor for sudden cardiac death? Findings from the KIHD Study. J Atheroscler Thromb. (2017) 24:6008. doi: $10.5551 /$ jat. 37184

34. Goldberg L, Tirosh-Wagner T, Vardi A, Abbas H, Pillar N, Shomron $\mathrm{N}$, et al. Circulating MicroRNAs: a potential biomarker for cardiac damage, inflammatory response, and left ventricular function recovery in pediatric viral myocarditis. J Cardiovasc Transl Res. (2018) 11:31928. doi: 10.1007/s12265-018-9814-0

35. Ihara Y, Hayabara T, Sasaki K, Fujisawa Y, Kawada R, Yamamoto T, et al. Free radicals and superoxide dismutase in blood of patients with Alzheimer's disease and vascular dementia. J Neurol Sci. (1997) 153:7681. doi: 10.1016/S0022-510X(97)00172-X

36. Lu MC, Fang WC, Li WC, Yeh WC, Shieh YH, Chen JY. The association between insulin resistance and cardiovascular disease risk: a communitybased cross-sectional study among taiwanese people aged over 50 years. Int J Environ Res Public Health. (2020) 17:7195. doi: 10.3390/ijerph17197195

37. Heymsfield SB, Wadden TA. Mechanisms, pathophysiology, and management of obesity. N Engl J Med. (2017) 376:254-66. doi: 10.1056/NEJMra1514009

38. Lin X, Zhang X, Guo J, Roberts CK, Mckenzie S, Wu WC, et al. Effects of exercise training on cardiorespiratory fitness and biomarkers of cardiometabolic health: a systematic review and metaanalysis of randomized controlled trials. J Am Heart Assoc. (2015) 4:e02014. doi: 10.1161/JAHA.115.002014

39. Holloszy JO. Exercise-induced increase in muscle insulin sensitivity. J Appl Physiol. (1985) 99. (2005) 338-43. doi: 10.1152/japplphysiol.00123.2005

40. Rietman A, Schwarz J, Tome D, Kok FJ, Mensink M. High dietary protein intake, reducing or eliciting insulin resistance? Eur J Clin Nutr. (2014) 68:9739. doi: 10.1038/ejcn.2014.123

41. Cersosimo E, Solis-Herrera C, Trautmann ME, Malloy J, Triplitt CL. Assessment of pancreatic $\beta$-cell function: review of methods and clinical applications. Curr Diabetes Rev. (2014) 10:2-42. doi: 10.2174/1573399810666140214093600

42. Cree-Green M, Xie D, Rahat H, Garcia-Reyes Y, Bergman BC, Scherzinger $\mathrm{A}$, et al. Oral glucose tolerance test glucose peak time is most predictive 
of prediabetes and hepatic steatosis in obese girls. J Endocr Soc. (2018) 2:547-62. doi: 10.1210/js.2018-00041

43. Mitrakou A, Kelley D, Mokan M, Veneman T, Pangburn T, Reilly J, et al. Role of reduced suppression of glucose production and diminished early insulin release in impaired glucose tolerance. N Engl J Med. (1992) 326:229. doi: 10.1056/NEJM199201023260104

44. Praveen EP, Chouhan S, Sahoo J, Goel SK, Dwivedi SN, Khurana ML, et al. Effect of different insulin response patterns during oral glucose tolerance test on glycemia in individuals with normal glucose tolerance. Diabetes Technol Ther. (2016) 18:316-26. doi: 10.1089/dia.2015.0379

45. Heiskanen MA, Motiani KK, Mari A, Saunavaara V, Eskelinen JJ, Virtanen $\mathrm{KA}$, et al. Exercise training decreases pancreatic fat content and improves beta cell function regardless of baseline glucose tolerance: a randomised controlled trial. Diabetologia. (2018) 61:1817-28. doi: 10.1007/s00125-018-4627-x

46. Kahleova H, Tura A, Klementova M, Thieme L, Haluzik M, Pavlovicova $\mathrm{R}$, et al. A plant-based meal stimulates incretin and insulin secretion more than an energy- and macronutrient-matched standard meal in type 2 diabetes: a randomized crossover study. Nutrients. (2019) 11:486. doi: 10.3390/nu11030486

47. Sarwar N, Danesh J, Eiriksdottir G, Sigurdsson G, Wareham N, Bingham S, et al. Triglycerides and the risk of coronary heart disease: 10,158 incident cases among 262,525 participants in 29 Western prospective studies. Circulation. (2007) 115:450-8. doi: 10.1161/CIRCULATIONAHA.106.637793

48. Wycherley TP, Moran LJ, Clifton PM, Noakes M, Brinkworth GD. Effects of energy-restricted high-protein, low-fat compared with standard-protein, lowfat diets: a meta-analysis of randomized controlled trials. Am J Clin Nutr. (2012) 96:1281-98. doi: 10.3945/ajcn.112.044321

49. Parks EJ, Parks EJ. Changes in fat synthesis influenced by dietary macronutrient content. Proc Nutr Soc. (2002) 61:2816. doi: 10.1079/PNS2002148

50. Kelley GA, Kelley KS, Tran ZV. Aerobic exercise and lipids and lipoproteins in women: a meta-analysis of randomized controlled trials. J Womens Health. (2004) 13:1148-64. doi: 10.1089/jwh.2004.13.1148

51. Vanhees L, Geladas N, Hansen D, Kouidi E, Niebauer J, Reiner Z, et al. Importance of characteristics and modalities of physical activity and exercise in the management of cardiovascular health in individuals with cardiovascular risk factors: recommendations from the EACPR. Part II. Eur J Prev Cardiol. (2012) 19:1005-33. doi: 10.1177/1741826711430926

52. Pan B, Ge L, Xun YQ, Chen YJ, Gao CY, Han X, et al. Exercise training modalities in patients with type 2 diabetes mellitus: a systematic review and network meta-analysis. Int J Behav Nutr Phys Act. (2018) 15:72. doi: 10.1186/s12966-018-0703-3

53. Tjønna AE, Lee SJ, Rognmo, ø., Stølen TO, Bye A, Haram $\mathrm{PM}$, et al. Aerobic interval training versus continuous moderate exercise as a treatment for the metabolic syndrome: a pilot study. Circulation. (2008) 118:346-354. doi: 10.1161/CIRCULATIONAHA.108. 772822

54. Dieli-Conwright CM, Courneya KS, Demark-Wahnefried W, Sami N, Lee K, Buchanan TA, et al. Effects of aerobic and resistance exercise on metabolic syndrome, sarcopenic obesity, and circulating biomarkers in overweight or obese survivors of breast cancer: a randomized controlled trial. J Clin Oncol. (2018) 36:875-83. doi: 10.1200/JCO.2017.75.7526

55. Keating SE, Machan EA, O'connor HT, Gerofi JA, Sainsbury A, Caterson ID, et al. Continuous exercise but not high intensity interval training improves fat distribution in overweight adults. J Obes. (2014) 2014:834865. doi: 10.1155/2014/834865

56. Rye KA, Barter PJ. Predictive value of different HDL particles for the protection against or risk of coronary heart disease. Biochim Biophys Acta. (2012) 1821:473-80. doi: 10.1016/j.bbalip.2011.10.012

57. Fisher G, Brown AW, Bohan Brown MM, Alcorn A, Noles C, Winwood L, et al. High intensity interval- vs. moderate intensity- training for improving cardiometabolic health in overweight or obese males: a randomized controlled trial. PLoS ONE. (2015) 10:e0138853. doi: 10.1371/journal.pone.0138853

58. Lemieux I, Lamarche B, Couillard C, Pascot A, Cantin B, Bergeron J, et al. Total cholesterol/HDL cholesterol ratio vs. LDL cholesterol/HDL cholesterol ratio as indices of ischemic heart disease risk in men: the Quebec cardiovascular study. Arch Intern Med. (2001) 161:268592. doi: 10.1001/archinte.161.22.2685

59. Yokokawa H, Yasumura S, Tanno K, Ohsawa M, Onoda T, Itai K, et al. Serum low-density lipoprotein to high-density lipoprotein ratio as a predictor of future acute myocardial infarction among men in a 2.7 -year cohort study of a Japanese northern rural population. J Atheroscler Thromb. (2011) 18:8998. doi: 10.5551/jat.5215

60. Khalafi M, Symonds ME. The impact of high-intensity interval training on inflammatory markers in metabolic disorders: a meta-analysis. Scand J Med Sci Sports. (2020) 30:2020-36. doi: 10.1111/sms.13754

61. Forsythe LK, Wallace JM, Livingstone MB. Obesity and inflammation: the effects of weight loss. Nutr Res Rev. (2008) 21:117-33. doi: 10.1017/S0954422408138732

62. Christiansen T, Paulsen SK, Bruun JM, Pedersen SB, Richelsen B. Exercise training versus diet-induced weight-loss on metabolic risk factors and inflammatory markers in obese subjects: a 12-week randomized intervention study. Am J Physiol Endocrinol Metab. (2010) 298:E824831. doi: 10.1152/ajpendo.00574.2009

63. Wright CS, Zhou J, Sayer RD, Kim JE, Campbell WW. Effects of a highprotein diet including whole eggs on muscle composition and indices of cardiometabolic health and systemic inflammation in older adults with overweight or obesity: a randomized controlled trial. Nutrients. (2018) 10:946. doi: $10.3390 /$ nu10070946

Conflict of Interest: The authors declare that the research was conducted in the absence of any commercial or financial relationships that could be construed as a potential conflict of interest.

Publisher's Note: All claims expressed in this article are solely those of the authors and do not necessarily represent those of their affiliated organizations, or those of the publisher, the editors and the reviewers. Any product that may be evaluated in this article, or claim that may be made by its manufacturer, is not guaranteed or endorsed by the publisher.

Copyright (c) 2021 Chen, Hsu, Chien and Chen. This is an open-access article distributed under the terms of the Creative Commons Attribution License (CC BY). The use, distribution or reproduction in other forums is permitted, provided the original author(s) and the copyright owner(s) are credited and that the original publication in this journal is cited, in accordance with accepted academic practice. No use, distribution or reproduction is permitted which does not comply with these terms. 